\title{
THE EVOLUTIONARY HYPOTHESIS.
}

\author{
By B. D. Hakn, D. D.
}

\section{The Plathorm.}

(First of three Lectures on the Norton Foundation, 1922)

The range of these lectures is necessarily limited. Only three phases of the grand hypothesis come under review,- they are the Platform, Process, and Connection of Evolution. Properly there should be a definition of the subject at the outset. So great is the variation and so difficult the expression of the ideas entertained that any definition is likely to be unsatisfactory, but since the method of research demands always an immediate efficient cause, the account of the general law is that of an automatic advance, from the simple to the complex, by virtue of resident forces. There is therefore a predisposition on the part of naturalists to set aside final causes, and to deny orthogenesis, that is, design and contrivance in nature. This definition of evolution as an automatic, mechanistic process, however individuals may protest, is still the most serviceable for discussion and is thrust upon the attention of the student at every step of investigation.

Today we are concerned with the platform on which the immense mechanism is to be installed. Will the lot accommodate the plant? Will the factory hold the machinery: Is the solar system large enough to accommodate the hypothesis? Is there power and time enough to provide for the biological development? The sun is our light, furnace and dynamo, and the stratified earth the field of its effects. The earth with its resident heat is, I believe, a negligible factor, and our first inquiry turns our attention to the great dynamo, and our second object of inquiry is the stratified earth, the field of its effects. 
The material, energy and age of the sun are critical issues for the doctrine of evolution.

Matter is the marvel and mystery of present research. We can realize the enormous fuel requirement to operate the solar system by the simple statement that every gram of matter in the sun loses two calories of heat annually, or 75,000 H.P. per square yard. At this rate of radiation the sun should be darkened in a few thousands of years. A ball of carbon of the same size would be consumed in less than three thousand years. It is evident that this lavish expenditure of energy cannot be sustained by the sun to meet the requirements of historic time. Mayer assumed that the sun was replenished by a continual supply of meteorites, but astronomers inquired "Where will you find your meteorites"? For a moment physicists saw some relief in the suggestion of Helmholtz. The contraction of the mass of the sun was a source of heat far greater than that of ordinary combustion. Gravitation, so to say, squeezed out the internal heat. But this source was also inadequate. If it was one hundred times more potent than free combustion, with a quantity of energy fifteen million times the annual radiation, that energy would be dissipated in one million years. But the time, according to the geologic program, would not account for the deposition of a single stratum of the crust of the earth.

Now the surface temperature of the sun is $6,000 \mathrm{de}$ gres C. Until it was possible to rival that temperature by the electric are we could only speculate about gases at sun temperatures. But now they are brought within the range of the laboratory. One most important discovery about incandescent gases was Stefan's law that radiation is the fourth power of the absolute temperature; that is, for every increase of temperature the power of radiation is multiplied sixteen times. A sun of twice the mass, or double the temperature, could add but one-eighth to the 
period of geologic time. The possible radiant heat, the mass, the pressure and density of the sun, all have limits approximately ascertained. Above a certain temperature the sun must cease to be a planet with its size and density (atomic weight 110) clearly known. The greatest period through which it has exercised its power is about 910,000 years. In about 160,000 years when its radius shall have contracted 1-100 of a degree, the temperature of the earth at the equator will be 26 degrees $C$. In 850,000 years the radius of the sun will have contracted 1-50 and the temperature at the equator will be 0 degrees C., freezing.

But the hopes of natural scientists have revived with the discovery of radio active substances, and the power of the Crook's tube. Speculation is again rife and not less adventurous. We have discovered that the atom can be rent asunder. That the process is accompanied with a release of energy that hurls away the corpuscles of the atom with the speed of light. Atomic dissociation, simple combustion, yields an insignificant amount of energy compared with ionic dissociation. It was at once assumed that here was a source of energy ample for all biological and geological demands. Sir Oliver Lodge very confidently asserted that this sub-atomic dissociation will explain the enormous resources of the sun. By actual experiment it has been found that the co-efficient of subatomic dissociation is six times that of combustion. One gram of hydrochlorine by molecular dissociation (combustion) yields 22,000 calories, but with atomic dissociation 144,000 calories. Now although atomic dissociation is six times at potent as molecular, which makes possible less than 3,000 years of duration for the sun, the 20,000 gained by atomic dissociation is still not enough. Accordingly some scientists have assumed another, a protoatom, and dissociation to account for the geological sun. The declaration of Prof. Briner, of the University of Geneva, is illuminating: "Now that we know the fabulous 
amount of energy set free during the atomic disintigration of radio active substances, under this last supposed form, chemical phenomena may participate in no mean degree in the maintenance of solar radiation'.

It is to be remembered that this proto-atomic realm is a matter of pure speculation. It has been assumed because all known sources of heat have failed. It is but rhyming with the facts of radio activity. But it is an admission that radio activity will not supply the sun with the energy demanded for geological time. It is further to be remembered that the spectroscope has nothing to say of radio activity in the sun, that each kilogram must contain two milligrams of radium, that each gram of the sun furnished $2,000,000,000$ of calories, that the corpuscles, ions, or electrons of the atomic system are held to be incorporeal, are but centers of electric force, have ceased to be substances and, with apologies to metaphysicians, are but dynamic relativities. Therefore it would appear that matter has ceased as substance by our experimental method, and is translated into a branch or mode of dynamics. Under these conditions the hope of verifying a sub-atomic realm of transcendental powers to explain our very substantial sun and indefinitely lengthen the period of his existence, according to the demands of our geologists for a lease of eternity, is not very bright in a world which has evaporated under the electric arc into that relativity called force.

Recently a biologist asked a physician what latitude in the matter of time, in his judgment, might be presumed for geological formations. The reply was, "One billion of years". Now the life period of radium is some 1,700 years, and of uranium 1,000,000,000 of years, and of thorium $10,000,000,000$ of years. Why did he say $1,000,000,000$ ? I suppose that the radium period was all too short and the thorium period was all too long, but the uranium period about to his taste. Great is the value of 
expert authority. Should you see a train passing at fortyfive miles an hour and you were asked "How far has it come"? - and you should say, "Forty-five miles".-_your answer would be as authoritative and trusworthy.

Now it is evident that every possible source of the tremendous energy required of the sun to meet the exactions of the evolutionary proposal is exhausted. Although radium in its reduction supplies $10,000,000,000$ times the energy of any chemical dissociation, a radium sun could not supply the necessary heat. Radio activity has opened up unsuspected resources of dynamics, and scientists have imagined yet another realm of further disintigration which shall disclose a proportionally greater reservoir of heat and power. One authority affirms that our sun has continued for billions of years. He says, "We know it". Manifestly, if we know it, this earnest search to vindicate such a statement is superfluous. Even so, this authority is moved to a star shower of figures rivaling the hail storm of meteors of 1833. By these speculations the case is appealed from the known to the unknown, but we learn something in the art of dogmatism and speculation, that is, to posit a finer transcendental universe to stop a leak in a favorite hypothesis. It would tax the resources of Betelguese to operate the evolutionary geology of the schools.

Perhaps it would be more precise to name this topic of geology the evolutionary program. The point I make is that the strata of the earth give evidence which is inconsistent with this idea of stupendous geological ages.

Let me recall the history of the construction of the geological progress. The first observers in this field of research presumed that the order of the strata was an order of time. The lowest stratum was the oldest. Each superposed stratum was deposited in later time. Also innocently they presumed that the strata, each in its turn, was deposited the whole world around, that is, they as- 
sumed what Mr. Spencer ironically named "the onion coat" idea of geology. The world was successively incrusted with identical strata. But it was soon evident that the texture of the rocks could not be depended upon to identify the strata. Rocks which were chemically and mechanically identical with the earliest formations, appeared in the later formations. But geologists found another and in their judgment an unfailing test of the age of the strata. Biology furnished the means of discrimination. The ages were designated eozoic, mesozoic and cenozoic, and their subordinate strata were defined by the evolutionary advance of living forms. The most ancient rocks were destitute of life, and each later age was distinguished by the fossils embedded in the strata. Thus with a perfected schedule of biological advance, from the simple to the complex forms of life, the perspective of the ages was revealed. But the same presumption of one world-wide distribution of these distinctive forms in each stratum is another form of the onion coat theory, and dominates the reasonings of geologists. The world is 'still put into successive plaster casts, only each succeeding investment is distinguished by fossils instead of the texture of the rocks. Beds of the same texture, by this test, are assigned to different ages. In the same formation, in what appears to be the same deposit, one part is assigned to another period because of the fossils contained in the rocks.

Mr. Darwin estimated that $60,000,000,000$ years must be assigned for the Cambrian deposits. Compare this statement with another, namely, that any later formation may overlie archaic rocks. Now in every such case evidence of intervening time is lost, and when the beds lie conformably there is evidence that there was no intervening age.

Water is the great agent of geology,-I may say, the exclusive agent. By water the power of the sun is ap- 
plied to tear down the heights and distribute the detritus in the plains. But for water the earth, like the moon, would have been a world of ranges and peaks and angles and edges with monotonous plains between. On this watered planet the crystal mills and conveyors are in perpetual operation. The water works cannot be turned off. In every clay bank in the hills, in the mountains, are the evidences of its sculpture. Slopes and gullies and ravines and gorges and canyons mark its action. Its cutters are rain and rivers and the dredging currents of the seven seas. So we were taught, so we have believed. When rocks have been exposed for millions of years they are worn into slopes, gullies and gorges. When another stratum is spread upon the exposed formations, the new stratum must fill up all the hollows and escarpments of the older rock. The new stratum then will not lie conformably upon the old. But when they lie conformably there are no hollows and gorges and slopes to be filled up by the new material. This is the hand of the geologic clock. Any overlying conformable stratum was immediately formed. The bed rock had no opportunity to weather. Geologically speaking, there was no intervening time. Exploration and research have found ancient rocks overlaid conformably by recent strata, pre-Cambrian rocks covered conformably by cretaceous strata. Now if the Cambrian formation requires $60,000,000,000$ years, 300,000,000,000 years is a small allowance of time for the intervening ages between these widely separated formations. Was the action of water suspended, that the ancient pre-Cambrian formations should be protected from erosion, or was the water carefully and judiciously poured over the sand stones and shales in even sheets so that there should be no runnels or rivers formed, or were the rocks blanketed? If successive formations are evidence of a lapse of time, when ancient formations are overlaid conformably by more recent strata, the succes- 
sion is instant and time is cancelled. One instance wrecks the assumption of distinct geological ages. But there are many such formations, and there are yet more facts against the doctrine just as convincing. There are instances where jurassic rocks are interposed between carboniferous strata. Did the geological process make a leap over into jurassic time?--and then reverse?-and begin over again? What shall we say of the famous thrustfaults-a later discovery of science? In the northern part of this continent for 7,000 square miles the strata are upside down: also from eastern Tennessee down into Georgia, and in other places throughout the world. In the northwest pre-Cambrian rocks overlie conformably cretaceous beds. These overlying rocks are not strata. They are the Rocky Mountains imposed upon cretaceous plains. The classic explanation propounded in our schools is, there was a fracture and the edges were depressed, and somehow there came a great lateral pressure, and instead of the cretaceous plain crumpling up before the mountain, the mountains reared up and slid over the plains for a distance of from fifteen to twenty miles. The earlier explanation was that the mountains were thrust up into the heavens and fell over; that is, they pancaked. But with the Rocky Mountains sliding over the cretaceous plains, what would become of the cretaceous forces? What of the shales under such pressure? With that pressure and heat they would have been transformed into Plutonic rocks like gneiss and granite.

It was with entire disbelief and scorn that as a boy I heard that once Greenland had a tropical climate. As a man I have been compelled to admit that the coal measures of Greenland, Spitzbergen and Alaska prove that tree ferns and cycads flourished in the Arctic Circle in carboniferous times. Does it occur to you that these plants could not flourish in a land of months of night? Further evidence is at hand that tropical conditions, 
these same conditions, prevailed. Tropical shell fish are scattered all about the polar regions. If tree ferns cannot endure a temperate climate, they could not last through a protracted night. They could not endure the seasonal change. There is one inevitable inference from these facts. There was no seasonal change. There was no arctic night. The inclination of the poles of the earth did not obtain. Something tremendous happened to this earth in tertiary times, so-called, and the ancient arctic flora and fauna perished.

Other important facts, which contradict the accepted geological program must be omitted, but if the strata of the world contradict the assumption of geological ages, are the contained fossils good evidence of those ages? Since the texture of the rocks does not distinguish the formations, and the forms of life are the test of the order of the strata, do the fossils appear in such order and abundance that the schedule can be determined by their occurrence?

One of the most notorious difficulties of geology has been the disappearance of species. The ages are distinguished by the prevalence of distinct forms of life. At the end of each age there must be wholesale slaughter of these typical forms. The ages must be not only characterized by the order of beings prevailing, but also they must be distinguished by the absence of others. The ages can be sundered only as the vital succession is broken. Translated into geology this proposal means a world cataclysm at the end of each age. Periodic convulsions are essential to operate the hypothesis as orderly procedure is necessary for its maintenance. A stroke of the tremendous geological cleaver must fall to mark the progress of geological time. Yet by the biological hypothesis the vital sequence must be continuous. There is a certain nicety in this adjustment of the two factors of this binary hypothesis that would please a watchmaker. Naturally 
we ask, "Does biology live up to these exacting specifcations"'

Fifty years ago, when this science was still young, the fossils qualified for their part. They are not so amenable to discipline at the present time. They are found in quantity at the end of each age. They are scattered through the period. Sporadic fossils are rare,- they lie in beds. Fishes and crustaceans and mammals lie in shoals and herds. So sudden is the disaster which overwhelms them that the fishes do not lie straight and stark as dead fishes do, but in the poses of life and spasmodic action. They were suddenly covered and died in suffocation. Otherwise they had rotted and their skeletons would have been disjointed or yet more likely they would have been devoured. These tidal sweeps, which though swim. mers could not resist, rushed hundreds of miles inland and to unmeasured heights against the mountain barriers. And that tide was charged with mud and silt and gravel so that the whole living mass was buried deep, and by slow disintegration their molds were filled up and made the artistic casts which we call fossils. So thorough and world-wide was the catastrophe that whole species and genera were annihilated.

Meanwhile life, all forms of life, were not destroyed. The vital bond of the ages must not be broken. There is something cunningly selective about this geologic disaster. It is a sublime display of utter, ruthless, exterminating force, with a whispered proviso in it. The next age must begin with something, and something distinctive, in the forms of life. The prevalent species must be swept away and the rare and promising species preserved in the same disaster. Somewhere nature must have a private sanctuary for the elect, a safe and quiet spot at the heart of the cyclone. Her savage mood is checked by hesitation and consideration.

But says the geologist, "Bear in mind, we have al- 
ways said that the record of the fossils is necessarily im. perfect". But not so imperfect that we do not have among the fossils not only young and old, but also their embryos. How then is it in any age, with its uniform flora and founa the world around, that the intermediate of the species, the rarer forms, were not swept down in the world tide? Imperfection, accidental imperfection, is one thing; but a discriminated imperfection of record is a very different thing.

Then the new age begins on a higher vital plane,-not with the spared remnant of the dominant species, but with selected representatives of higher forms already developed in that past age and spared in the wholesale disaster. Or shall we speculate and say that the environment was so changed that the older species were put to it to live up to the new conditions and so the species were transformed I hand out this suggestion of grace. With Mendelism in mind, as our youths say, "I wonder if 1 will get a bite".

Now it is not this or that species, but whole genera that are destroyed according to the record of the rocks. Nevertheless the chosen ones escaped. They appear in the new formation as if they had never been. There are Silurian, Triassic, Jurassic species and genera which never appear again as fossils. Yet they live. Fosstls have the infamous habit of overleaping the ages, evading subsequent, wholesale, world-wide cataclysm and reappearing in this recent age. They show an amazing agility. Now those species which never reappear in the rocks are dead and done for in the record. But advanced research has discovered their representatives alive at the present time in the ocean depths. If whole genera were wiped out, according to the record of the rocks, what right have species of those genera to be flourishing ages since their destruction and swimming about in the high seas? 
The expedition of the challenger marks the beginning of a new field of research, namely, the ocean depths. Some of the results of these investigations have a distinct influence upon our view of geology. We have learned that the ocean currents do not dredge and distribute sand, silt or gravel. Our great gulf streams in the Atlantic and Pacific scarcely disturb the depths. Everywhere beyond the famous hundred fathom line about the continent there is neither sand nor silt nor gravel. Everywhere there is either peculiar red clay or globergina ooze upon the ocean floor. The depths are silent and still. Therefore, the ocean as a geological agent is insufficient in its action to account for strata and erosion. Plainly the seven seas never went to work on the planetary job, or they have struck.

Rivers make no discrimination between ancient and recent rocks. Where their channels cross different formations the river beds are uniform and continuous. They also destrop the distinction, the time distinction, between rock formations.

The ocean currents then do not dredge the ocean floor nor do they distribute sediment in strata. The rivers are indifferent to the kind of rocks they erode. The later strata ovedlie the earlier conformably. Strata are found displaced, interposed, and reversed. The vital series, as attested by the fossils, the marks alike of strata and time, the keepers of the geolical annals, are destroyed, both genera and species, young, old, and the unborn, and lie in the fossil beds where representatives of the flora and fauna of later strata are not found, yet have they escaped the general destruction and initiate a new biological age. It is incredible that these rare and new forms should escape a world-wide disaster to replenish the desolation of the new era. It is a multiple incredibility that representatives of the exterminated species and genera should repeatedly escape all these catastrophes and be found alive in our recent seas. 
Our free burning sun is unable to supply the heat of our geological ages. By contraction he cannot fulfill the requirements. A radio active sun is also declared to be inadequate. And a proto-atomic sun is the magnificent speculation to amend a desperate situation.

There is one suggestive fact which makes plain the geological situation and unifies these several hypothetical world catastrophes. Let me recall the fact that there were tropical conditions within the arctic circle throughout the geological ages; also the fact that tropical flora and fauna could not endure a protracted night. Is it not evident, therefore, that there were not in those times our seasonal changes? Is it not, therefore, evident that at the conclusion of the geological periods the pole of the earth was swung 27 degrees from its ancient plane of rotation? So that geology and the tradition of the races combined to affirm one grand disaster in which a tidal rush of the seas overwhelmed all lands and swept away species and genera. There was one age, not many; there was one world with diverse regions, flora and fauna. Instead of one procession of beings through tremendous ages common to the whole world, there were many genera and tribes distributed in various habitats, and one adequate sun burning and contracting in the heavens above them. 